\title{
Trabalhos cientificos de Adolpho Lutz, publicados ou inéditos
}

\section{Siglas utilizadas}

BAL Biblioteca Adolpho Lutz

BMN Biblioteca do Museu Nacional

BN Biblioteca Nacional

BC Biblioteca Central - Fiocruz

BCF Biblioteca do Castelo - Fiocruz

IAL Instituto Adolfo Lutz - São Paulo. Possui coleção encadernada dos trabalhos de Adolpho Lutz fotocopiados à época das comemorações do centenário de seu nascimento, por iniciativa de Bertha Lutz. Possui também coleção dos filmes que deram origem às fotocópias.

Centenário - Comissão do Centenário de Adolpho Lutz/Conselho Nacional de Pesquisas. Adolpho Lutz (1855-1955): vida e obra do grande cientista brasileiro. Rio de Janeiro, Jornal do Commercio, Rodrigues \& Cia., 1956, 55p.

Neiva - Arthur Neiva. Necrológio do professor Adolpho Lutz (1855-1940). Rio de Janeiro, Imprensa Nacional, 1941. Reimpresso das Memórias do Instituto Oswaldo Cruz, t. 36, fas. 1, pp. i-xxiii, 1941. Apêndice: bibliografia organizada por Herman Lent em 1935 e corrigida por Neiva e Owermeer. "Algumas lacunas existem, muito poucas, porém de vulto; não foram preenchidas por falta de elementos."

Memórias - Carlos Chagas, 'Adolfo Lutz' e 'Bibliografia do dr. Adolpho Lutz', Memórias do Instituto Oswaldo Cruz, t. XVIII, fas. 1, 1925, pp. i-vii, viii-xxii. I.

Discípulos - Ao dr. Adolpho Lutz. Em homenagem aos 35 anos de atividade científica. Seus discípulos e admiradores, s.l.n., 1913, 17p.

Bertha - Listagem contida em Neiva, mas atualizada à mão.

Lista - 'Lista dos trabalhos e estudos feitos no Instituto Bacteriológico e não publicados' (caixa 25). Documento datilografado (5p.) com carimbo do Departamento de Saúde do Estado, Divisão Administrativa, Secretaria. "Copiado por Djanira Pessoa; conferido por Aparecida F. Romeiro".

Relação - "Relação de documentos que se referem ao sr. Adolpho Lutz, retirados do arquivo antigo do extinto Serviço Sanitário, entregues no gabinete do sr. dr. diretor geral, nesta data, 24.11.40". Documento datilografado (3p.) com carimbo do Departamento de Saúde do Estado, Divisão Administrativa, Secretaria. "Relacionado por Djanira Pessoa; visto B. Araújo (chefe de seção)". 
1885 - 'Über eine neue, in Brasilien beobachtete Krankheit', Gesells. dtchr. Naturf. u. Aerzte Tagebl. 58. Versammlung, 58, 21. September 1885, pp. 428-9. Strassburg.

Centenário

OBS. Tudo indica que são os Anais do $58^{\circ}$ Congresso (Versammlung) promovido por uma sociedade (Gesells. dtchr...). Suspeita-se de que o autor da nota publicada em 1886 tenha sido L. Hoffmann, que assina a nota publicada, em seguida, sobre sífilis.

1885 - 'Über eine Rhabdonemaart des Schweines, so wie über den Befund der Rhabdonema strongyloides (Anguillula intestinalis und stercoralis) beim Menschen in Brasilien', Centralblatt für klinische Medicin, 6.6.1885, vol. 6, no 23, pp. 385-90. Separata: pp. 1-5.

BAL 1 original.

BMN 1 original (L975).

IAL Cópia fotostática, vol. 2, no 1, pp. 6-11.

Resumos Gaz. hébd. Méd. Paris, 22(4), p. 653, 1885. Rec. Méd. Vét., Paris, 64(7), pp.

47-8, 1887. Ann. Méd. Vét., Bruxelas, 35(6), p. 343.

1885 - 'Über Ankylostoma duodenale und Ankylostomiasis', em Richard von Volkmann, Sammlung Klinischer Vorträge in Verbindung mit deutschen Klinikern, Innere Medicin no 62-92. Leipzig, Druck und Verlag von Breitkopft und Härtel, 1885: 255-6 (Innere Medicin, no 88), pp. 2295-350; 265 (Innere Medicin, nº 92), pp. 2467-506, 4 pranchas.

BAL 2 cópias fotostáticas do Serviço de Documentação, Reitoria da Universidade de São Paulo, Departamento de Cultura e Ação Social, ref. 4041n-535731.

IAL cópia fotostática vol. 2, no 1, pp. 1-100.

Centenário Há resumos em Deutsche medizinal Zeitung., 76:6, 1886; resumo por R. von Hoesslin em Münch. med. Wschr., 33:397, 1886; resumo por Riess em Berl. klin. Wschr., 458, 1886.

Memórias Há resumos em Deutsche medizinal Zeitung., 76:6, 1886; resumo por R. von Hoesslin em Münch. med. Wschr., 33:397, 1886; resumo por Riess em Berl. klin. Wschr., 458, 1886.

1885-86 (21.12) — Über in Brasilien beobachtete Darmparasiten des Schweines und anderer Hausthiere, sowie über das Vorkommen derselben Arten beim Menschen', Deutsche Zeitschrift für Thiermedizin, vol. 12, no 1-2, pp. 61-2. Leipzig.

BAL 1 cópia fotostática do Serviço de Documentação, Reitoria da USP, Dep. de Cultura e Ação Social, ref. 3933n-53SY3644.

IAL Cópia fotostática vol. 2, nำ 1, pp. 12-3.

BCF folha 305. BC ref. 2212(7) - relativa a 1885.

Centenário Consta a data 1885-1886. A referência a dia e mês encontra-se no verso da cópia fotostática, que não traz o ano.

1886 - '58. Versammlung deutscher Naturforscher und Ärtze in Strafsburg 1885. III'. 'Über eine neue, in Brasilien beobachtete Krankheit', Monatsheftefür Praktische Dermatologie, 1886, vol. 5, no 1, pp. 32-3.

BAL 2 cópias fotostáticas oriundas do Serviço de Documentação, Reitoria da USP,

Dep. de Cultura e Ação Social, ref. 3933n-53SY3644, e da Surgeon's Office

Library, 115391, respectivamente. +1 original separata.

IAL Cópia fotostática vol. 2, no 2 2, pp. 145-7. 
Caixa 22, Texto traduzido para o português. Faltam pp. 1, 2 e 3. Primeira versão da pasta 256, tradução, ainda sem revisão, em texto datilografado, com apenas as 8 primeiras maço 8 páginas, na mesma pasta.

Centenário Consta que o trabalho foi publicado originalmente em Monatsheftefür Praktische Dermatologie, 1886, pp. 77-100. Resumos em Vierteljabrsschrift Derm. Syph., no 18, 1886, pp. 331-4; por Carl Hochsinger em Ann. Derm. Syph., no 7, pp. 425-7; e em Friedländer's Fortschritte der Medizen (Kokkothrix leprae), 1886. Jber. Fortsch. path. Milkroorg., 2: 250-1, 1886.

1886 - 'Üeber die Beziehungen zwischen Stäbchen und Coccen', Fortschritte der Medicin Unter Mitwirkung Hervorragender Fachmänner herausgegeben von dr. Carl Friedländer Privatdocent der Pathol. Anatomie. Berlim, Verlag von Fischer's medicinischer Bachhandlung, vol. 4, nº 10, pp. 327-31.

BAL cópia fotostática da Reitora da USP, Dep. de Cultura e Ação Social, Divisão de Documentação, ref. 174. Outra cópia fotostática, com frontispício.

IAL cópia fotostática vol. 2, noㅡ 2, pp. 137-41.

Centenário consta que há resumo em Jber. Fortschr.path. Mikroorg., 2, 1886, p. 366 (ou Baumgarten's Jahresbericht).

1886 - 'Über einen sprosspilzartigen Epiphyten der menschlichen Haut (Mikrosporon anomoeon Vidal)', Monatshefte für Praktische Dermatologie, vol. 5, no 2, pp. 72-3. Trabalho produzido e publicado em Hamburgo.

BAL 2 cópias fotostáticas.

IAL cópia fotostática vol. 2, no 2, pp. 142-3.

Centenário Há resumos em Arch.Derm. Syph. (Wien), no 18, 1886, p. 887; e em Jber. Fortschr. path. Mikroorg., no 2, 1886, p. 338.

$\mathbf{1 8 8 7}$ - Resenha: 'Report on Leprosy in Trinidad by Beaven Rake, Port of Spain 1886'. Monatshefte für Praktische Dermatologie, vol. 6, no12, 1887, pp. 968-9. Hannover.

BAL 2 cópias fotostáticas +1 cópia fotostática.

1887 - Resenha: 'An Abstract of lectures on Lepra by J. L. Bidenkap. London, Williams \& Norgate, 1886'. Monatshefte für Praktische Dermatologie, 6:653-61, Hamburgo. Trabalho realizado em São Paulo.

BAL 1 cópia fotostática completa +1 incompleta.

1887 - 'Mitteilungen über Lepra Nach in Brasilien gemachten Beobachtungen von dr. Adolph Lutz in Limeira, Brasilien', Monatshefte für Praktische Dermatologie, vol. 6, no 9, 1.5.1887, pp. 38793, 504-20, 546-60. Hamburgo. Tradução em português, com manuscritos da tradução. Inclusive nota de Bertha a Gualter, que parece ser o autor da tradução. Caixa 22, pasta 256, maço 8 (40 laudas).

BAL 2 cópias fotostáticas do Serviço de Documentação, Reitoria da USP, Dep. de Cultura e Ação Social, ref. 648-54 (em uma delas falta a última página).

IAL cópia fotostática, vol. 2, no 2 , pp.153-92.

Centenário consta que há versão em Annales de Dermatologie et Sylphiligrafie (Études sur la Lèpre en Brésil), noำ, pp. 569, 576-82, 784, 796-801. 
1888 - 'Zur Frage der Uebertragung des menschlichen Spulwurmes. Weitere Mittheilungen von dr. Adolpho Lutz in São Paulo', Centralblatt für Bakterologie und Parasitenkunde, ano II, vol. 3, nº 14, 1888, pp. 425-8. Jena. Rodapé de Leuckart, p. 427. Trabalho realizado em São Paulo.

BAL 1 original (separata) + 1 fotocópia do artigo do Serviço de Documentação, Reitoria da USP, Dep. de Cultura e Ação Social, ref. 3933n 53 SY8644.

IAL cópia fotostática vol. 4, pp. 1-4.

1888 - 'Sul modo di trasporto dell'Ascaris lumbricoides', Giornale della R. Accademia di Medicina di Torino, ano 51, vol. 36, n⿳ 2-3, pp. 84-6. Torino, Stamperia dell'Unione Tipografico-Editrice, 1888.

BAL 1 cópia fotostática obtida do Surgeon's Office Library -122225.

Centenário 'Sul modo di trasporto dell'Ascaris lumbricoides', Giornale della R. Accademia di Medicina di Torino, 51, pp. 35-6; no 2-3, pp. 84-6. Seria resumo do trabalho anterior.

1888 - 'Nachtrag zu menier lezten Mitteilung über die Invasion von Taenia elliptica und Ascaris, Centralblatt für Bakterologie und Parasitenkunde, ano II, vol. 3, no 10, 1888, pp. 299-300.

BAL 1 cópia fotostática.

IAL cópia fotostática vol. 4, pp. 36-7.

1888 - Weiteres zur Frage der Uebertragung des menschlichen Spulwurmes von Adolph Lutz', Centralblatt für Bakteriologie und Parasitenkunde, ano II, 1888, 1aㅡ parte, vol. 3, no 9, pp. 265-8; 2 $2^{\text {a }}$ parte (final), no 10, pp. 297-9. Trabalho realizado em São Paulo, em 7.1.1888. Parece ser uma resposta a trabalho de Grassi publicado no mesmo periódico (Bd. I, 1887, p. 131).

BAL 1 cópia fotostática de cada número, do Serviço de Documentação, Reitoria da USP, Dep. de Cultura e Ação Social, ref. 3834n53SY 3527 + 1 fotostática sem identificação.

IAL cópia fotostática vol. 4, pp. 45-51.

Centenário Consta que há resumo em O Brazil-Medico, no 3, 1889, pp. 96-104.

1888 - 'Zur Frage der Uebertragung von Taenia elliptica', Centralblatt für Bakteriologie und Parasitenkunde, ano II, vol. 3, no 16, 1888, pp. 489-90, Jena. Trabalho realizado em São Paulo.

BAL 2 cópias fotostáticas, uma do Serviço de Documentação, Reitoria da USP, Dep. de Cultura e Ação Social, ref. 3834n - 53SY3527 + 1 cópia fotostática.

IAL cópia fotostática vol. 4, pp. 38-9.

1888 - A opilação ou bypoemia intertropical e sua origem ou Ankylostoma duodenale e ankylostomiase. Rio de Janeiro, Tipografia Machado, 1888, 131p., 6 figs. Trabalho realizado em São Paulo.

IAL cópia fotostática vol. 3, nº 1, pp. 1-71; no 2, pp. 1-146. O livro é dedicado a Azevedo Lima. Várias páginas com anotações manucritas de autoria não identificada. Livro com carimbo da biblioteca do Instituto Bacteriológico e do Instituto de Higiene de São Paulo.

$\mathrm{BC}$ ref. 616.995132 .7 . 
1889 - 'Relatório sobre as investigações de ascaridíase humana de A. Lutz ... pelo dr. J. F. Monteiro', $O$ Brazil-Medico, Revista Semanal de Medicina e Cirurgia, ano III, 1889, pp. 96-104.

1890 (?) - 'Eine neue Nahtmethode von dr. Adolph Lutz in Honolulu (Mit 1 Abbildung)', Monatshefte für Praktische Dermatologie, vol. 10 (Jan.-Juni): 304-7. Hamburgo.

BAL 1 cópia fotostática.

IAL cópia fotostática vol. 4, pp. 58-61.

1890 - 'Zur Kasuistik des Rhinoskleroms von dr. A. Lutz zur Zeit Honolulu'. Monatshefte für Praktische Dermatologie, vol. 11, nํㅡㄹ 15.7.1890, pp. 49-51. Hamburgo.

BAL 2 cópias fotostáticas.

IAL cópia fotostática vol. 4, pp. 62-4.

1890 - 'Report of dr. A. Lutz to dr. J. H. Kimball, President of the Board of Health'. Biennial Report of the President of Health to the Legislature of the Hawaiian Kingdon, session of 1890, pp. 69-83. Honolulu, Printed by Hawaiian Gazette Co., 1890.

BAL 1 exemplar original +1 cópia fotostática.

IAL cópia fotostática vol. 4, pp. 65-79.

1891 - 'Zur Behandlung der Atherome', Dermatologische Wochenschrift, pp. 505-6.

BAL 1 cópia fotostática.

1891 - 'Zur Kenntniss der Amöben-Enteritis und - Hepatitis von dr. A. Lutz in Honolulu (Hawai)', Centralblatt für Bakterologie und Parasitenkunde, ano X, no 8 (seção intitulada 'OriginalMittheilungen'), 5.9.1891, pp. 241-8. Trabalho realizado em 15.6.1891.

BAL 2 fotocópias que trazem informações interessantes sobre o periódico + texto em alemão datilografado por iniciativa de Bertha e tradução para o português, com marcas de revisão à mão.

IAL cópia fotostática vol. 4, pp. 80-7.

1891-92 - 'Korrespondenz aus Honolulu', Monatshefte für Praktische Dermatologie, no 13 , pp. 389-92 (Sept. 1891); 488-90 (Sept. 1891); no 14, pp. 30-4 (Sept. 1891); 152-5 (Sept. 1891); 275-7 (Nov. 1891); 307-11 (Nov. 1891); no 15, pp. 382-9 (escrito em San Francisco, em 10.8.1892). Hamburgo.

BAL 3 cópias de cada segmento (do Serviço de Documentação, Reitoria da USP, Dep. de Cultura e Ação Social, ref. 3933n-53 Sy3644) + outra série da Army Medical Library, Washington (falta p. 154 e a p. 155 está repetida).

IAL cópia fotostática vol. 4, pp. 88-95, 96-8, 99-101, 102-6, 107-11, 112-5, 116-9. Centenário Inclui as 'Nodosidades juxta-articulares', de Lutz, 14:30-4. Resumo em Jber. Fortschr. Path. Mikroorg., 8:271.

OBS. Digitamos texto que foi datilografado por ordem de Bertha, e que se encontra na caixa 20, pasta 252, maço 5. Na caixa 2, temos cópias fotostáticas deste segmento usadas provavelmente em exposição sobre lepra. Bertha também providenciou tradução para o inglês. 
1893 - 'Weiteres zur Lebensgeschichte des Distoma hepaticum von dr. A. Lutz in San Francisco, Calif.', Centralblatt für Bakteriologie und Parasitenkunde, vol. 13, nำ10, pp. 320-8. Jena. Trabalho realizado em San Francisco, Califórnia.

BAL 2 cópias fotostáticas, uma delas do Serviço de Documentação, Reitoria da USP, Dep. de Cultura e Ação Social, ref. 3834n - 53 SY 3527.

IAL cópia fotostática vol. 5, pp. 34-42.

1893 - 'Über den methodischen Salolgebrauch bei Phthisis florida und bei gelbem Fieber von dr. A. Lutz in San Paulo, Brasilien', Fortschritte der Medicin, vol. 11, no 23, Dez. 1893, pp. 925-9, Berlim. Trabalho realizado em São Paulo.

BAL 2 cópias fotostáticas.

IAL cópia fotostática vol. 5, pp. 43-7.

Centenário Há resumo em Jhber. Fortschr. path. Mikroorg. 9:780, 1894. Em BAL, 1 cópia fotostática deste trabalho.

(s.d.) - 'Hawaii, arquipélago distante'. Conferência proferida em São Paulo. Originais datilografados e revistos por Gualter Adolpho Lutz. Trabalho inédito. Caixa 33, pasta 244, maço 4.

BAL 1 cópia datilografada.

1893 - 'Relatório do Instituto Bacteriológico de S. Paulo (referente ao ano de 1893). Apresentado em 2 de janeiro de 1894 '.

BAL caixa 25, pasta 227, maço 1: texto datilografado (na folha de rosto consta como "Anexo 1"). Incluído em Relatório do Instituto Bacteriológico, São Paulo, Imprensa Official do Estado, 1895 (ver abaixo).

IAL Cópia fotostática vol. 5, pp. 55-63.

OBS. 'Febre amarela', encontrado na pasta 212f, maço 4, é um trecho extraído do relatório referente a 1893.

1893 - 'Relatório sobre o cólera-morbus em São Paulo, capital e cidades do interior do estado, pelo dr. Adolpho Lutz, 1893'. Referência em 'Relação de documentos que se referem ao sr. Adolpho Lutz', caixa 25.

1894-95 - Instituto Bacteriológico de S. Paulo. Apresentado ao diretor do Serviço Sanitário. Escrito em 3 de março de 1895, referente ao ano de 1894 e aos dois primeiros meses de 1895 , pp. 29-40. Caixa 25.

BAL 1 cópia datilografada.

IAL cópia fotostática vol. 5, pp. 64-75.

1894 - 'Beobachtungen über die als Taenia nana und flavopunctata bekannten Bandwürmer des Menschen von dr. Adolph Lutz in St. Paulo (Brasilien)', Centralbatt für Bakteriologie und Parasitenkunde, vol. 16, no 2, pp. 61-7. Jena. Trabalho realizado em São Paulo.

BAL 1 fotocópia.

IAL cópia fotostática vol. 5, pp. 48-54.

Resumo 'Taenia nana und flavopunctata (abstract of Lutz, 1894)', Journal of the Royal Micr[oscopical/obiological] Society, Londres, 2 s., vol. 14, (6), Dec. 1894, p. 687. 
1896 - Em colaboração com Arthur Mendonça: 'Mormo em São Paulo. Verificação bacteriológica da existência do mormo em São Paulo pelos drs. Adolpho Lutz e Arthur Mendonça. Trabalho do Instituto Bacteriológico do Estado de S. Paulo'. São Paulo, Typographia do Diario Official, 6p., pp. 3-8. Trabalho escrito em 22.7.1896.

BAL 1 cópia fotostática do Serviço de Documentação, Reitoria da USP, Dep. de Cultura e Ação Social, ref. 42-54S(ou 8)Y 296.

IAL cópia fotostática vol. 5, pp. 84-9.

Centenário Foi publicado também em O Brazil-Medico, Revista Semanal de Medicina e Cirurgia, 10, pp. 418-20.

1896 - 'Relatório apresentado ao dr. director do Serviço Sanitário do Estado de São Paulo pelo dr. Adolpho Lutz, director do Instituto Bacteriológico de São Paulo - 1896'. Relatório datado de fevereiro de 1897. Caixa 25, pasta 16, maço 1.

BAL Texto datilografado.

1896 - Introdução ao livro (pp. 3-5) Contribuição ao estudo da febre amarella. A urina do doente de febre amarella pelo dr. J. Bonilha de Toledo, formado pela Faculdade de Bruxellas, médico adjunto do Instituto Bacteriológico. São Paulo, Typographia do Diário Official, 141p.

BAL 1 exemplar original.

1897 - Relatorio apresentado ao dr. director geral do Serviço Sanitario pelo dr. Adolpho Lutz em 26 de agosto de 1897 sobre os institutos e trabalbos de bygiene no Rio da Prata. São Paulo, Typographia do Diario Official, 1897, 12p.

BAL 1 fotocópia (sob no 40). Caixa 25, pasta 16, maço 2: originais manuscritos deste relatório + várias anotações em papel almaço. Parece que parte deste material foi usada no relatório de 1894, e tem a ver com a epidemia de cólera.

IAL cópia fotostática vol. 5, pp. 91-100.

1897 - Em colaboração com A. Mendonça e Bonilha de Toledo: Parecer do Instituto Bacteriologico do Estado de São Paulo sobre o Serum, apresentado pelo sr. dr. Phelippe Caldas. São Paulo, 24 de maio de 1897. São Paulo, Typographia do Diario Official, 8p. Publicado também como 'Serum contra a febre amarela proposto pelo dr. Philippe Caldas. Parecer dos drs. Adolpho Lutz, Arthur Mendonça e Bonilha de Toledo, diretor e ajudantes do Instituto Bacteriológico do Estado de São Paulo'. O Brazil-Medico, Revista Semanal de Medicina e Cirurgia, vol. 11, nº 30, ago. 1897, pp. 268-9.

BAL 1 cópia original do folheto.

IAL cópia fotostática vol. 5, pp. 101-6.

1897 - Relatório apresentado pelo dr. Adolpho Lutz, director do Instituto Bacteriológico do Estado, acerca de sua commissão em Montevidéo por occasião da conferencia do dr. Sanarelli, relativa à descoberta do microbio da febre amarella. São Paulo, Typographia do Diario Official, 10p. Trabalho redigido em São Paulo em 27.7.1897.

BAL cópia original do folheto +1 cópia fotostática.

IAL cópia fotostática vol. 5, pp. 107-14.

Centenário Foi reimpresso como 'Sobre o bacilo icteroide de Sanarelli', O Brazil-Medico, Revista Semanal de Medicina e Cirurgia, Rio de Janeiro, 11:424-7, 1897. 
JAIME L. BENCHIMOL, MAGALI R. SÁ, JOHANN BECKER et alii

1898 - 'Observações sobre a epidemia de febre amarela do núcleo colonial Campos Salles'. Abr. 1898. Referência em 'Lista dos trabalhos e estudos feitos no Instituto Bacteriológico e não publicados' (caixa 25).

1898 - Trabalbos do Instituto Bacteriologico do Estado de São Paulo durante o anno de 1898 pelo dr. Adolpho Lutz. Relatorio apresentado ao dr. director do Serviço Sanitario de São Paulo. São Paulo, Escola Typographica Salesiana, 1898, 16 p.

BAL 1 cópia fotostática.

IAL cópia fotostática vol. 6, pp. 14-28.

Centenário Foi reimpresso em Revista Médica de São Paulo. Jornal Pratico de Medicina, Cirurgia e Hygiene, no 11, 2:308-21, 1899. BAL - temos 1 exemplar deste trabalho.

OBS. Foi reimpresso em Revista Médica de São Paulo. Jornal Pratico de Medicina, Cirurgia e Hygiene, no 11, 2:308-21, 1899. BAL - temos 1 exemplar deste trabalho: Lutz assina o relatório em janeiro de 1899, mas, na folha de rosto, a data de publicação é 1898. Centenário indica 1899. Sobre a publicação deste relatório, ver ofícios na caixa 25 , pasta 16 , maço 1 . Possuímos cópia datilografada na caixa 26, pasta 227, maço 1 . Em, Lista dos trabalhos inéditos realizados no Instituto Bacteriológico, consta: Lutz, Adolpho, 'Relatório dos trabalhos do Instituto Bacteriológico durante o anno de 1898'.

1899 - 'Um caso de myiase ou bicheira da garganta', Revista Médica de São Paulo. Jornal Pratico de Medicina, Cirurgia e Hygiene, 2(8):215-9, 2 quadros. Trabalho consta da 'Lista dos inéditos realizados no Instituto Bacteriológico' (caixa 25).

BAL 2 exemplares.

IAL vol. 6, pp. 29-33.

1899 - 'Relatório dos trabalhos do Instituto Bacteriológico em 1899'. 'Lista dos inéditos realizados no Instituto Bacteriológico' (caixa 25).

1900 - 'Peste bubônica em São Paulo', Rev. Med. Cirur., (1):35-8, Rio de Janeiro.

BAL Cópia datilografada na caixa 22, pasta 256, maço 8 (5 laudas).

Centenário 'Peste bubônica em São Paulo'. Rev. Med. Cirur. (1):35-8, Rio de Janeiro.

1900 - Instituto Bacteriologico do Estado de S. Paulo. Instrucções relativas aos exames e analyses que podem ser requisitados do Instituto Bacteriologico do Estado de São Paulo pelo dr. Adolpho Lutz. Publicações da Revista Médica de S. Paulo. São Paulo, Escola Typographica Salesiana, 4p. Publicado originalmente em Revista Médica de São Paulo. Jornal Pratico de Medicina, Cirurgia e Hygiene, ano 3, no 2, pp. 28-31.

BAL $\quad 12$ exemplares do folheto original.

IAL vol. 6, pp. 34-8.

1900 - 'Instituto Bacteriológico de São Paulo — Relatório de 1900'. Datado de janeiro de 1901.

BAL Texto datilografado com correções à mão de autoria não identificada na caixa 25, pasta 227, maço 1. Outra cópia no maço 2, com correções feitas (supõe-se) por Bertha. Em 'Lista dos trabalhos inéditos realizados no Instituto Bacteriológico' consta: Lutz, Adolpho. 'Relatório dos trabalhos do Instituto Bacteriológico 1899 e outro de 1900'. 
1902 - 'Cópia do relatório de 1902, enviado em 26 de janeiro de 1903 à diretoria do Serviço Sanitário. Dr. Carlos Meyer'. Em 'Lista dos trabalhos e estudos feitos no Instituto Bacteriológico e não publicados' (caixa 25) consta: Lutz, Adolpho'. 'Relatório dos trabalhos do Instituto Bacteriológico em 1902'.

BAL

Texto datilografado. Caixa 25, pasta 227, maço 1. Observação a lápis: copiado de manuscrito do dr. C. Meyer. Outra cópia no maço 2, com correções feitas (supõe-se) por Bertha.

1902 - 'Relatório de investigações em Araçariguaba sobre diversas moléstias, pelo dr. Adolpho Lutz'. Referência em 'Relação de documentos que se referem ao sr. Adolpho Lutz', caixa 25.

1902 - Em colaboração com A. Splendore, 'Üeber Pebrine und verwandte Mikrosporiden. Ein Beitrag zur Kenntnis der brasilianischen Sporozoeen', Centralblatt für Bakteriologie, Parasitenkunde und Infektionskrankheiten, vol. 33, no 2, pp. 150-7, 1 ilust. Jena. Tradução para o italiano: 'Pebrina e microsporidi simiglianti. Contribuizione alla conoscenza degli Sporozoari brasiliani', Revist. Pat. Veg., Portici, 10, 1903.

BAL 1 separata original. Também em BC, ref. 593.195 + 1 cópia fotostática: Centralblatt für Bakteriologie, Parasitenkunde und Infektionskrankheiten, $\mathrm{Bd}$. XLVI. Heft 4, pp. 311-5, il.

Resumos Münch. med. Wschr., 50(3):124, 1903. Bull. Inst. Pasteur, Paris. 1(2):62, 1903.

1903 - Nota preliminar sobre os insectos sugadores de sangue observados nos estados de São Paulo e Rio de Janeiro. Publicações do Brazil-Medico. Rio de Janeiro, Typ. Besnard Frères, 1903. Publicado originalmente em O Brazil-Medico, Revista Semanal de Medicina e Cirurgia, 17(29):281-2.

BAL 2 separatas, pp. 2-9.

IAL vol. 6, pp. 60-7.

Arquivo Separata da $2^{\mathrm{a}}$ ed., com anotações a lápis de Lutz. Pasta entomologia médica; Bertha Lutz versão para o inglês, datilografada.

1903 - Em colaboração com Carlos Meyer e J. P. Barreto, 'Estudo microbiológico das águas das cabeceiras do Tietê', 1903. Referência em 'Lista dos trabalhos e estudos feitos no Instituto Bacteriológico e não publicados' (caixa 25).

BAL Temos cópia na caixa 25, pasta 156, maço 6.

1903 - 'Waldomosquitos und Waldmalaria', Centralblatt für Bakteriologie, Parasitenkunde und Infektionskrankheiten, vol. 33, no 4, pp. 282-92, 7 figs. Jena. Trabalho realizado em São Paulo em 16.9.1902. Tradução para o inglês e português: 'Mosquitos da floresta e malária silvestre', Revista Brasileira de Malariologia, 2 (2):91-100, figs.1-7, 1950.

BAL

cópia fotostática incompleta da publicação em alemão, contendo as pp. 282-3, 288-9 e uma outra cópia fotostática, contendo as pp. 282-91.

Também em BMN e BC, ref. 616.936. Em BAL um exemplar original da Revista Brasileira de Malariologia. A pasta 85 do Arquivo Adolpho Lutz contém: versão em inglês revista por Bertha e destacada da Rev. B. de Malariologia. Tradução em português datilografada, com cópia incompleta. Texto datilografado com cópia da versão em inglês de Bertha. Texto datilografado a partir da tradução em inglês, com marcas de revisão (versão anterior à publicada na revista). Texto datilografado incorporando as correções 
1904 - Synopse e systhematisação dos mosquitos do Brasil. a) Quadro dos Generos da Família Culicidae (p. dupla); b) Catálogo dos Culicídeos Brasileiros e Sul-Americanos (pp. 1-16); c) Euculicidae: Chave para a Determinação dos Gêneros encontrados no Brasil (pp. 1-7); e) Chave para a Determinação dos Gêneros da Sub-familia "Culicinae" Observados no Brasil (pp. 1-3); f) Chave para a Determinação das Espécies de Euculicidae encontradas no Brasil (não incluindo Culicinae) (pp. 1-6); g) Chave para a Determinação das Espécies da Sub-familia Culicinae (1-5); h) Quadro das Espécies encontradas na Bahia, Alagoas, Pernambuco, Parahyba, Ceará e Manáos (pp.1-4). Em 'Mosquitos do Brasil', tese de C. Bourroul, Bahia, 1904, p. 33 e ss.

BAL 1 cópia fotostática.

IAL vol. 7, pp. 1-43.

Arquivo Divisão Díptera: fotocópia. Pasta Culicidae: os manuscritos originais, inclusive Bertha Lutz textos de Bourroul emendados por Lutz. Encontra-se aí também uma versão datilografada do trabalho de Lutz. Uma pasta com descrições em alemão que podem ser inéditas.

1904 - Em colaboração com Alfonso Splendore, 'Ueber Pebrine und verwandte Mikrosporidien (Nachtrag zur ersten Mitteilung. Bd. XXXIII, no 2, p. 150 e ss.)', Centralblatt für Bakteriologie, Parasitenkunde und Infektionskrankbeiten, vol. 36, nº 5, pp. 645-50, 1 ilust., 2 tabs.

BAL 4 separatas originais. Também em BC ref. 2245(22) + 1 cópia fotostática.

IAL vol. 7, pp. 44-51.

Centenário Há resumos em Bull. Inst. Pasteur, Paris, 2:905; Münch. med. Wschr., 1:124.

1904 - Em colaboração com Carlos Meyer, 'Analyse microbiologica das aguas na serra do Bom Successo. 1904'. Referência em 'Lista dos trabalhos e estudos feitos no Instituto Bacteriológico e não publicados' (caixa 25).

BAL Na caixa 25, pasta 156, maço 6 encontra-se o trabalho 'Águas de propriedade do cidadão Abílio Soares em Conceição de Guarulhos', 4.10.1904.

1904 - 'Relatório sobre a administração e os trabalhos do Instituto Bacteriológico durante o ano de 1904'. Texto datilografado datado de 31.12.1904, junto com ofício de 16.1.1905, encaminhando relatório a Ribas. Também ofício de 12.12.1904, prometendo entrega do relatório e solicitando aquisição de aparelhos e objetos. Em 'Lista dos trabalhos e estudos feitos no Instituto Bacteriológico e não publicados' (caixa 25) consta: 'Lutz, Adolpho. Relatório dos trabalhos do Instituto Bacteriológico em 1904'.

BAL Texto datilografado na caixa 25, pasta 227, maço 1 . Outra cópia no maço 2 com correções feitas (supõe-se) por Bertha.

1904 - Em colaboração com Carlos Meyer, 'Relatório do exame bacteriológico das águas colhidas nas cabeceiras dos rios Claro, Pinheirinho e São João', jan.-fev. 1904. Referência em 'Lista dos trabalhos e estudos feitos no Instituto Bacteriológico e não publicados' (caixa 25).

BAL

Caixa 25 (fora), pasta 156, maço 6.

1904 - 'Sobre o poder bactericida do anosol. 1904 (pp. 389-91, cop. 1902-04. II.VIII.1904)'. Referência em 'Lista dos trabalhos e estudos feitos no Instituto Bacteriológico e não publicados' (caixa 25). 
1906 - 'Relatório sobre a administração e os trabalhos do Instituto Bacteriológico de São Paulo durante o ano de 1906'. Consta em 'Lista dos trabalhos e estudos feitos no Instituto Bacteriológico e não publicados' (caixa 25): 'Lutz, Adolpho. Relatórios dos trabalhos do Instituto Bacteriológico em 1906'.

BAL Texto datilografado na caixa 25, pasta 19, maço 3. Também pasta 227, maço 1.
Junto com o da pasta 19, ofício de 27.6.1906 encaminhando "o original do
relatório referente à comissão à Europa (ver referência anterior) de que fui
incumbido pelo governo deste estado em setembro do ano próximo findo".
Observação de Bertha Lutz: "Durante parte deste ano o cargo de diretor foi
exercido pelo dr. Meyer; daí ser este relatório bastante diferente, menos
científico e mais estatístico do que ele (Lutz) costumava fazer. Meyer,
trabalhador ótimo, tinha grande pendor pela estatística, que Lutz costumava
definir 'a mentira em algarismos'." Junto ao relatório da pasta 227, ofício
datado de 8.1.1907, encaminhando o relatório a Ribas. Outra cópia no maço
2 com correções feitas (supõe-se) por Bertha. Na mesma pasta, maço 2: "O
dr. Carlos Meyer no Serviço Sanitário do Estado de São Paulo", uma espécie
de currículo de suas atividades lá. Ainda (maço 1): Produtos químicos
analisados no Bacteriológico; folhetos impressos, 1896: "Chinosol - A powerful
Germicide - Bacteriological Report", produzido por uma empresa de Londres,
"Analytical Laboratory", situada em Apothecaries Hall, Blackfriars. Do mesmo
produto, folheto em espanhol da "Franz Fritzche y Cia., fábrica de productos
químicos, aceites essenciales y esenciais" de Hamburgo.

1906 - 'Observações anatômicas e microscópicas feitas em casos de meningite cérebro-espinhal epidêmica. Trabalho do Instituto Bacteriológico', Revista Médica de São Paulo. Jornal Pratico de Medicina, Cirurgia e Hygiene, ano 9, no 7, pp. 132-6. Consta como inédito em 'Lista dos trabalhos e estudos feitos no Instituto Bacteriológico e não publicados' (caixa 25).

BAL 1 cópia fotostática. Cópias datilografadas (2) na caixa 27, pasta 18, maço 2.

IAL vol. 8, pp. 24-8.

1907 - 'Resumo dos trabalhos do Instituto Bacteriológico de São Paulo, de 1892 a 1906', Revista Médica de São Paulo. Jornal Pratico de Medicina, Cirurgia e Hygiene, ano 10, no 4, 28.2.1907, pp. 65-88. Em Centenário, consta: "não assinado, talvez de autoria do dr. Carlos Meyer". Consta também, como trabalho de Lutz, 'Relatório dos trabalhos do Instituto Bacteriológico em 1907'.

BAL 1 cópia fotostática.

IAL vol. 8, pp. 29-52.

1907 - 'Relatório sobre a administração e os trabalhos do Instituto Bacteriológico durante o ano de 1907'. Em 'Lista dos trabalhos e estudos feitos no Instituto Bacteriológico e não publicados' (caixa 25) consta: 'Lutz, Adolpho. Relatórios dos trabalhos do Instituto Bacteriológico em 1907'.

BAL Texto datilografado datado de 31.12.1907. Junto, ofício de 10.1.1908, encaminhando o relatório a Ribas. Obs.: "copiado do copiador". Caixa 25, pasta 227, maço 1. Outra cópia no maço 2 com correções feitas (supõe-se) por Bertha. 
1908 - Estudos e observações sobre o quebrabunda ou peste de cadeiras pelo dr. Adolfo Lutz. Extraído da Revista da Sociedade Scientífica de S. Paulo (Brazil), 1908, vol. 3, nº 3-7. São Paulo, Typographia Henrique Grobel, 1908, pp. 34-58. Publicado também como 'Estudos e observações sobre o quebrabunda ou peste de cadeiras', Diário Oficial do Estado do Pará (Belém), vol. 17, no 4.780, 1907, pp. 356-62.

BAL 1 original + 1 cópia fotostática, do Serviço de Documentação, Reitoria da USP, Dep. de Cultura e Ação Social, ref. 609-54. Também em BC, ref. 863, 1908. A versão publicada em Belém encontra-se em BC, ref. 2245 (14); BCF, ref. 0254 , caixa 27 , f. 607.

IAL vol. 8, pp. 97-121.

1908 (1909?) - Em colaboração com C. Meyer, Hematozoarios endoglobulares. Hématozoaires Endoglobulaires. Memoria apresentada no Sexto Congresso Brasileiro de Medicina e Cirurgia. Mémoire Présenté au Sixième Congrès Brésilien de Médicine et de Chirurgie. Paris, E. Delouche, s.d., 15p., 8 pranchas coloridas. Texto em francês e português. Referência em 'Lista dos trabalhos e estudos feitos no Instituto Bacteriológico e não publicados' (caixa 25) como trabalho inédito de 1908.

OBS.

Em Centenário consta 1907; em Neiva e Memórias, 1909. Apesar de constar do catálogo da Biblioteca da Fiocruz, não foi encontrado.

BAL 3 exemplares originais do libreto em grande formato e luxuoso + 1 cópia fotostática (com rótulo indicando $\mathrm{n}^{\circ} \mathbf{6 8}$ ).

IAL $\quad$ vol. 9, pp. 1-23.

Resumo O Brazil-Medico, Revista Semanal de Medicina e Cirurgia, 21(27), 1913, pp. 257-8.

1908 - Em colaboração com Carlos Meyer, 'Sobre os hematozoários endoglobulares dos pássaros, 1908'. Referência em 'Lista dos trabalhos e estudos feitos no Instituto Bacteriológico e não publicados' (caixa 25).

1908 - Uma mycose pseudococcidica localizada na bocca e observada no Brazil. Contribuição ao conbecimento das Hyphoblastomycoses americanas. Publicações do Brazil-Medico. Rio de Janeiro, Typ. Besnard Frères, 1908, 27p.

BAL 6 originais.

IAL vol. 9, pp. 24-31 (versão publicada em O Brazil-Medico).

Reimpresso $\quad$ Annais Brasileiros de Dermatologia e Sifilografia, vol. 20, no 2, 1945, pp.131-53.

OBS. Publicado originalmente como 'Uma mycose pseudococcidica localizada na bocca e observada no Brazil. Contribuição ao conhecimento das Hyphoblastomycoses americanas', O Brazil-Medico, Revista Semanal de Medicina e Cirurgia, ano 22, nำ13, pp. 121-4; no 15, pp. 141-4. Excetuandose o parágrafo de introdução, acrescentado, e dois parágrafos do texto original de 1908, suprimidos, é idêntico a: 'Coccidioides - Infektion mit Lokalisation in der Mundschleimhaut. Erste in Südamerika beobachtete Fälle. Beitrag zur Geschichte der Hyphoblastomycosis americana', Memórias do Instituto Oswaldo Cruz, vol. 28, no 4, 1934, pp. 585-601. E também à versão reimpressa em Annais Brasileiros de Dermatologia e Sifilografia, vol. 20, nํㅡ 2, 1945, pp. 131-53. 
Instituto Bacteriológico na exposição comemorativa do centenário da Abertura dos Portos. Em 1ำ de novembro de 1908, tornou-se chefe de serviço do Instituto Oswaldo Cruz, mas só se aposentaria do cargo de diretor do instituto paulista em 17.10.1913.

1909 — 'Tabaniden Brasiliens und einiger Nachbarstaaten', Zoologische Jabrbücher, supl. X (4):619-92 + 3 páginas duplas com estampas. col. Jena.

BAL 1 exemplar cópia fotostática. Também BMN.

IAL vol. 9, pp. 95-171.

Arquivo Pasta Tabanidae. Originais datilografados com correções feitas à mão.

Bertha Lutz

1909 - Em colaboração com Arthur Neiva, 'Erephopsis auricincta. Uma nova mutuca, da subfamilia Pangoninae. Erephopsis auricincta, Eine neue Tabanidenart aus der Subfamilie Pangoninae', Memórias do Instituto Oswaldo Cruz. Rio de Janeiro, t. 1, no 1, pp. 12-3, pl. I. Publicado em português e alemão.

BAL 1 cópia fotostática do Serviço de Documentação, Reitoria da USP, Dep. de Cultura e Ação Social, ref. 119-54 SY 294. Também em BC e BMN.

IAL vol. 9, pp. 172-4.

1909 - Em colaboração com Arthur Neiva, 'Contribuições para o conhecimento da fauna indíjena de Tabanidas. Beiträge zur Kenntnis der einheimischen Tabanidenfauna', Memórias do Instituto Oswaldo Cruz, t. 1, no 1, pp. 28-32. Publicado em português e alemão.

BAL 1 cópia fotostática do Serviço de Documentação, Reitoria da USP, Dep. de Cultura e Ação Social, ref. 117-54 SY 339. Também em BC e BMN.

IAL vol. 9, pp. 175-80.

1909 - 'Contribuição para o conhecimento das espécies brasileiras do gênero Simulium. Beitrag zur Kentniss der Brasilianischen Simuliumarten', Memórias do Instituto Oswaldo Cruz, t. $1, \mathrm{n}^{\circ}$ 2, pp. 124-46.

BAL Separata e exemplar da revista. 1 cópia fotostática do Serviço de Documentação, Reitoria da USP, Dep. de Cultura e Ação Social, ref. 43-54 SY 259, pp. 124-146. Também em BMN e BC.

IAL vol. 10, pp. 1-23.

Arquivo Na pasta Simuliidae, há uma versão em alemão que, segundo Bertha, não

Bertha Lutz corresponde àquela em português. Consta anotação: "Verificar se foi publicada alhures, ou se é inédito."

1909 - 'Collecção de tabânidas'. Em Instituto Oswaldo Cruz, Rio de Janeiro, Instituto Oswaldo Cruz, pp. 28-30. "This publication, including the article by Lutz, was issued anonymously" (Fairchild, G. B., 'The generic names for Tabanidae proposed by Adolfo Lutz', Psyche, Cambr., 57[4]: 117-27, 1951)'. Em G. B. Fairchild, 'The Adolpho Lutz Collection of Tabanidae (Diptera). I. The described genera and species, condition of the collection, and selection of lectotypes', Memórias do Instituto Oswaldo Cruz, 59(2), jul. 1961, pp. 185-249, inclui esta referência entre as obras de Lutz sobre tabanídeos, mas indaga, em nota de rodapé: "written by Lutz?".

$\mathrm{BC}$

1 original. 
Arquivo 1 separata. Originais datilografados. Texto em alemão completo; em português Bertha Lutz aparentemente incompleto. Pasta Tabanidade:

1912 - Em colaboração com A. Neiva, 'Contribuição para o conhecimento das espécies do gênero Phlebotomus existentes no Brazil. Zur Kenntnis der brasilianischen Phlebotomusarten', Memórias do Instituto Oswaldo Cruz, t. 4, no 1, pp. 84-95. Texto em português e alemão.

BAL 1 cópia fotostática do Serviço de Documentação, Reitoria da USP, Dep. de Cultura e Ação Social, ref. 180-54. Também em BC, BMN e BN: VI - 292,7,2, $\mathrm{n}^{\mathrm{o}} 2$.

Arquivo Pasta Dípteros. Subpasta Flebótomos: originais datilografados e manuscritos Bertha Lutz com correções; português e alemão.

1912 - Em colaboração com A. Neiva, 'Notas dipterolójicas. A propozito da Mydaea pici Macquart. Dipterologische Mitteilungen. Bemerkungen ueber Mydaea pici MacQuart', Memórias do Instituto Oswaldo Cruz, t. 4, no 1 , pp. 130-5.

BAL 2 exemplares originais da separata +1 cópia fotostática ( $\operatorname{sob} \mathrm{n}^{\circ}$ 84). Também em BC e BMN.

IAL vol. 10 , pp. 30-4.

1912 - História natural. Zoologia. Tabanídeos. Commissão de Linhas Telegraphicas Estrategicas de Matto Grosso ao Amazonas. Anexo 5. Rio de Janeiro, Papelaria Macedo, 1912, 9p., 1 pl. col.

BAL 13 originais +1 cópia fotostática do Serviço de Documentação, Reitoria da USP, Dep. de Cultura e Ação Social, ref. 117-54SY 329. Também em BMN, BN $-\mathrm{V} 147,7,9-\mathrm{n}^{\mathrm{o}} 2$; BC, ref. 6728.

Arquivo Originais datilografados incompletos + pedaço de uma prova tipográfica + Bertha Lutz um original datilografado.

1912 - 'A propósito da leishmaniose', Boletim da Sociedade Brasileira de Dermatologia (Rio de Janeiro), ano 1, no 1-2-3, pp. 50-1. Publicação trimensal dos Archivos Brasileiros de Medicina. Comunicação da 9ạ sessão ordinária.

BAL 1 original do periódico. Original datilografado desta nota na caixa 27, pasta 18, maço 1. Também em BC.

1912 - 'Sobre a Lepra pelo dr. Ad. Lutz', Boletim da Sociedade Brasileira de Dermatologia, Rio de Janeiro, ano 1, nำ1-2-3, p. 51. Publicação trimensal dos Archivos Brasileiros de Medicina. Comunicação da $9^{a}$ sessão ordinária.

BAL 1 cópia fotostática da comunicação e 1 original do periódico. Texto datilografado na caixa 20, pasta 252, maço 7 e na caixa 22, pasta 256, maço 4. Também em BC.

1912 - Instruções para colheita e conservação de material científico para estudo. II. Instruções para colbeita e conservação de hematófagos. Rio de Janeiro, Instituto Oswaldo Cruz, 1912, 7p.

BAL 11 originais do folheto +1 fotocópia.

Arquivo 2 folhetos.

Bertha Lutz 
1913 - 'Forest malaria', Proceedings of the Entomological Society of Washington, vol. 15, no 4, pp. $169-70$.

BAL 1 cópia fotostática. Texto datilografado, com trechos suprimidos na publicação, na caixa 23, pasta 83, maço 6. Também em BC.

1914 - 'Notas dipterolojicas. Contribuição para o conhecimento dos primeiros estados de tabanídeos brazileiros. Dipterologische Notizen. Zur Kenntnis der ersten Zustaende brasilianischer Tabaniden', Memórias do Instituto Oswaldo Cruz, t. 6, nº 1, pp. 43-9. Texto em português e alemão.

BAL 5 originais da separata + 1 cópia fotostática (sob no 96). Também em BMN e BC.

1914 - Em colaboração com A. Neiva, 'Contribuição para o estudo das Megarininae. II. Do Megarbinus haemorrboidalis (Fabricius, 1794). Beitrag zum Studium der Megarbininae II. Über Megarbinus haemorrboidalis (Fabricius, 1794)', Memórias do Instituto Oswaldo Cruz, t. 6, no 1, pp. 50-7, estampas coloridas n⿳⺈ 5-6. Texto em português e alemão.

BAL 1 exemplar original da separata +1 cópia fotostática do Serviço de Documentação, Reitoria da USP, Dep. de Cultura e Ação Social, ref. 121 54SY331. Também em BN, VI - 292,7,2, no 4; BC e BMN.

Arquivo 1 separata original.

Bertha Lutz

1914 - Em colaboração com A. Neiva, 'As Tabanidae do estado de Rio de Janeiro. Über die Tabaniden des Staates Rio de Janeiro', Memórias do Instituto Oswaldo Cruz, t. 6, no 2, 1914, pp. 69-80. Texto em português e alemão.

BAL 1 exemplar cópia fotostática (com rótulo indicando $n^{\underline{0} 98)}+3$ originais da separata. Também em BC.

Arquivo Pasta Tabanidae (segunda): originais datilografados em alemão.

Bertha Lutz

1914 - 'Contribuição para o conhecimento das Ceratopogoninas do Brazil. Aditamento terceiro e descrição de espécies que não sugam sangue. Terceira memória. Beitrag zur Kenntnis der Ceratopogoninen Brasiliens. Dritte Mitteilung Dritter Nachtrag und Beschreibung nicht blutsaugender Arten', Memórias do Instituto Oswaldo Cruz, t. 6, no 2, pp. 81-99, estampas coloridas nos 8 e 9. Texto em português e alemão.

BAL 1 exemplar original da separata +1 cópia fotostática do Serviço de Documentação, Reitoria da USP, Dep. de Cultura e Ação Social, ref. 36-54 SY 243. Também em BC.

Arquivo Pasta Chiro[...] - Ceratopogonidae: originais datilografados com revisões à

Bertha Lutz mão em português + explicação das estampas + rascunhos do trabalho manuscritos a lápis (pode ser tradução para o alemão). 
1915 - 'Tabânidas do Brasil e de alguns Estados vizinhos. Tabaniden Brasiliens und einiger Nachbarstaaten. Segunda memória', Memórias do Instituto Oswaldo Cruz, t. 7, no 1, pp. 51-119, 2 pranchas col. noㅗ 19 a 21. Texto em português e alemão.

BAL 1 cópia fotostática sob no 103 . Também em BMN e BC.

Arquivo Pasta Tabanidae: originais datilografados, português e alemão.

Bertha Lutz

1915 - Em colaboração com A. Neiva e A. Costa Lima, 'Sobre Pupipara ou Hippoboscidae de aves brasileiras', Memórias do Instituto Oswaldo Cruz, t. 7, no 2, pp. 173-99, 2 estampas.

BAL 1 cópia fotostática (sob no 104) do Serviço de Documentação, Reitoria da USP, Dep. de Cultura e Ação Social, ref. 118-54 SY 347. Também em BC e BMN.

Arquivo Pasta Pupipara: originais datilografados em alemão e português + provas Bertha Lutz tipográficas + fotos.

1916 - 'Observações sobre a evolução do Schistosomum mansoni', O Brazil-Medico, Revista Semanal de Medicina e Cirurgia, t. 30, no 49, pp. 385-7. Nota prévia.

$\mathrm{BC}$

(??).

1917 - 'Observações sobre a evolução do Schistosomum mansoni. Nota preliminar lida em 8 de novembro de 1916 na secção de sciencias biologicas da Sociedade Brasileira de Sciencias', Revista da Sociedade Brasileira de Sciencias, Rio de Janeiro, vol. 1, pp. 41-8.

BAL 1 cópia fotostática do Serviço de Documentação, Reitoria da USP, Dep. de Cultura e Ação Social, ref. 553-54. Também em BMN e BC.

1917 - Observações sobre a evolução do Schistosomum mansoni pelo dr. Adolpho Lutz (2 a nota prévia). Trabalho do Instituto Oswaldo Cruz. Rio de Janeiro, Manguinhos, 1917. Reimpresso do Brazil-Medico, ano XXXI, no 10, pp. 81-2 e no 11, pp. 89-90.

BAL 6 exemplares da separata. Também em BC.

1917 - 'Terceira contribuição para o conhecimento das espécies brasileiras do gênero Simulium. O piúm do norte (Simulium amazonicum)', Memórias do Instituto Oswaldo Cruz, t. 9, no 1, pp. 65-7, 1 pl.

BAL 1 exemplar original da separata. Também em BMN e BC.

Arquivo Pasta Simuliidae. Originais datilografados faltando pp. 1 e 2.

Bertha Lutz

1917 - 'Contribuições ao conhecimento dos Oestrideos brazileiros', Memórias do Instituto Oswaldo Cruz, t. 9, nº 1, pp. 94-113, estampas coloridas $\mathrm{n}^{\mathrm{os}} 27$ a 29. Este artigo foi traduzido e publicado como 'A contribution to the knowledge of Brazilian Oestridae', Memórias do Instituto Oswaldo Cruz, t. 10, no 2, pp. 118-37, 3 pranchas.

BAL 1 cópia fotostática do Serviço de Documentação, Reitoria da USP, Dep. de Cultura e Ação Social, ref. 119-54SY294. Também BC (em português) + 2 exemplares originais da separata (um em português e outro em inglês). Versão em inglês em BMN. 
1920 - 'Méthodo simples e prático de tratar o Empyema', A Folha Medica, vol. 1, oำ 1, p. 1.

BAL 1 cópia fotostática (com rótulo indicando nํㅜ 115). Cópia datilografada (parece ser do próprio autor) na caixa 27 , pasta 20 . Também em BC e BMN.

1920 - O emprego do phenol na technica microscopica pelo professor Adolpho Lutz. Separata de $A$ Folha Medica, ano 1, nos 5 e 7, 1920. Rio de Janeiro, Canton \& Beyer, 1920, 8p. 'On the use of phenol (carbolic acid) in microscopic technic. A new method of enclosing and preserving small objects for microscopic examination by Adolpho Lutz M. D.', Separata de A Folha Medica, ano 1, nํㅡ, 16.3.1920, 16p.

BAL 13 exemplares em português; 23 exemplares em inglês. Também em $\mathrm{BMN}$ e BC.

1920 - Novo methodo de fechar e conservar objetos pequenos destinados a exame microscopico pelo professor Adolpho Lutz. Separata de A Folha Medica, ano 1, no 3, 16.3.1920. Rio de Janeiro, Canton \& Beyer, 1920, 11p. il. Versão em inglês: vol. 2, no 15, pp. 116-7. Consta também 1939: 'A new method of enclosing and preserving small objects for microscopic examination'. Em volume jubilar para o professor Sadao Yoshida, 2:659-63, Publ. Osaka Nat. Hist. Soc. Inst. Research Microbic Dis. Osaka Imp. Unio. Japan.

BAL 4 originais. Também em BMN e BC.

1920 - Observação de vermes e larvas terrestres ou limicolas em ambiente transparente pelo professor Adolpho Lutz. Trabalho do Instituto Oswaldo Cruz. Separata de A Folha Medica, ano 1, $\mathrm{n}^{\circ}$ 3, 16.3.1920. Rio de Janeiro, Canton \& Beyer, 1920, 11p. il.

BAL 5 originais. Também em BMN, BC.

1920 - 'Considerações sobre a diphtheria', A Folha Medica, vol. 1, no 19, pp. 149-50; no 20, pp. 158-9; nำ 21, p. 168.

BAL cópia fotostática reúne o texto na íntegra (rótulo indica no 119). Também em BMN e BC.

1921 - 'Problemas que se ligam ao estudo da lepra'. Apresentado ao Congresso de Lepra e Dermatologia do Rio de Janeiro. Reproduzido em inglês em A Folha Medica, ano 2, 1921, pp. 115-6, 4 figs.

BAL Texto datilografado na caixa 20, pasta 252, maço 6. Na pasta que contém o texto datilografado, consta 1920. No alto de uma das páginas, lê-se "Congresso de 1921". Referência sem data.

1921 - 'Prevention of tropical diseases', cap. 10 de Nelson's Loose Leaf Living Medicine. New York/London, The Thomas Nelson \& Cia, pp. 365-78.

BAL 1 separata original

Centenário Houve nova edição em 1926. A data de publicação aqui e em Memórias é 1920. Nestas, o título é, contraditoriamente, dado como produção de 1921. Na separata consta "Reprint from Nelson's Loose Leaf Living Medicine. Copyright, 1921". Cópias datilografadas com correções manuscritas e prova tipográfica corrigida na caixa 27, pasta 53. Aí se encontra também uma folha manuscrita por Lutz em alemão, com anotação de Bertha: "Dermat?", tratando, ao que tudo indica, da "influência do vestuário". 
1921-22 - 'Reminiscências dermatológicas', A Folha Medica, vol. 2, no 19, pp. 145-6. Publicado também como Reminiscências dermatológicas. Segundo Congresso Sul-Americano de Dermatología y Sifilografia. Tip. San José 938, El Siglo Ilustrado, Montevideo, 1922.

BAL 1 cópia fotostática da versão publicada em $A$ Folha Medica do Serviço de Documentação, Reitoria da USP, Dep. de Cultura e Ação Social, ref. 190-54. 1 exemplar da versão uruguaia. Esta se encontra também em BMN e em BC (com data de 1921). Ver abaixo versão em inglês, Memórias do Instituto Oswaldo Cruz, 1946.

1921 - 'Sobre a ocorrência da Fasciola hepatica no estado do Rio de Janeiro', A Folha Medica, vol. 2, nº 11, pp. 81-2. Reimpresso como 'Sobre a ocorrência da Fasciola hepatica no estado do Rio de Janeiro', Boletim do Instituto Oswaldo Cruz. Supplemento das Memórias, ano I, t. I, fas.1, pp. 9-13.

BAL 2 exemplares do original da segunda versão. A primeira localizada em BC.

1921 - 'Motucas da Guaratuba', Boletim do Instituto Oswaldo Cruz. Supplemento das Memórias, ano I, t. I, fas. 1, p. 15.

BAL 1 exemplar do original.

Arquivo Pasta Tabanidae: originais datilografados em português.

Bertha Lutz

1921 - Resenha de Adolpho Lutz. Texto de Jahel, 'Dados sobre os principios e methodos modernos para demonstração dos spirochaetes no tecido especialmente nos centros nervosos', Münchner Medizinische Wochenschrift, no 32 (6 VIII 20), em Boletim do Instituto Oswaldo Cruz. Supplemento das Memórias, ano I, t. I, fas. 1, p. 29. Seção Resumos: anatomia e histologia pathologicas.

BAL 1 exemplar do original.

1921 - Resenha de Adolpho Lutz. Texto de Ricardo Fruehauf, 'Sobre a verificação de spirochaetes em ganglios lymphaticos', Wiener Klinische Wochenschrift, Jahrg. 33, no 46, em Boletim do Instituto Oswaldo Cruz. Supplemento das Memórias, ano I, t. I, fas. 1, p. 29. Seção Resumos: anatomia e histologia pathologicas.

BAL 1 exemplar do original.

1921 - Resenha de Adolpho Lutz. Texto de Jamaguti Tocunanga. 'Sobre a biologia dos bacillos da influenza', Deutsche Medizinische Wochenschrift, Jahrg. 46, no 49, p. 1357, em Boletim do Instituto Oswaldo Cruz. Supplemento das Memórias, ano I, t. I, fas. 1, p. 33-4. Seção Resumos: bacteriologia.

BAL 1 exemplar do original.

1921 - Resenha de Adolpho Lutz. Texto de A. Plehn, 'Novas pesquizas sobre a natureza da febre biliosa hemoglobinurica', Archiv für Schiffs-und Tropenhygiene, Bd. 24, no 11, 1920, p. 321, em Boletim do Instituto Oswaldo Cruz. Supplemento das Memórias, ano I, t. I, fas. 1, p. 44. Seção Resumos: etiologia.

BAL 1 exemplar do original. 
Adolpho Lutz foi um dos delegados (vocales) governamentais p. 18 aconselhou (v. p. 75) a realização de Conferência Internacional de Lepra entre os países americanos no Rio no ano próximo i.e., 1922 ... (?) comitê organizador a Delegação Brasileira o Departamento Saúde Público e o prof. Lindemberg." Em Neiva e Memórias, consta como trabalho de 1920: 'Problemas que se ligam ao estudo da lepra', A Folha Medica, ano 2, 1921, pp. 115-6, 4 figs. Apresentado ao Congresso de Lepra e Dermatologia no Rio de Janeiro, reproduzido em inglês. Centenário não faz referência a este texto, que deve ter sido publicado em 1922, e não em 1921. De acordo com Centenário, teria sido reimpresso em 'Actos culturales. La Universidad inaugura un Ciclo de Conferencias com la brillante exposición del sabio brasileño profesor Lutz', El Universal, Caracas, 10 de novembro de 1925, ano 17, no 5924, pp. 1-2. Na realidade, o artigo apresenta muitos comentários elogiosos sobre Lutz e alguém lê trabalho apresentado por Lutz no Rio, resumindo o jornal algumas de suas recomendações. Transcreve em alguns parágrafos comentário feitos de viva voz por Lutz.

1922 - Em colaboração com Oswaldo de Mello, 'Cinco novos escorpiões brasileiros dos generos Tityus e Rhopalurus, A Folha Medica, ano 3, no 4, pp. 25-6. Nota prévia.

\section{Em BMN e BC.}

1922 - Em colaboração com Oswaldo de Mello, 'Contribuição para o conhecimento dos escorpiões brasileiros. Descrição de uma espécie nova. Relação das espécies de Rhopalurus Thor que ocorrem no Brasil. Chave de classificação', A Folha Medica, ano 3, no 6, p. 41.

BAL 10 exemplares. Também em BC.

1922 - Em colaboração com Oswaldo de Mello (da filial de Belo Horizonte), 'Contribuição para o conhecimento dos escorpiões encontrados no Brasil. Espécies do genero Tityus C. L. Koch. Sinonymia, distribuição geográfica e chave systemática das mesmas'. Publicação separada de $A$ Folha Medica. Rio de Janeiro, Canton \& Beyer, 1922, 10p. Publicado em A Folha Medica, ano 3, no 10, pp. 73-4.

BAL 1 original da separata. Também em BC e BMN.

Arquivo Resumo em Simulidae 1.

Bertha Lutz

1922 - 'Zoologia médica pelo dr. Adolpho Lutz do Instituto Oswaldo Cruz'. Publicação separada de $A$ Folha Medica. Rio de Janeiro, Canton \& Beyer, 1922, 17p. 'Nematoceros hematófagos não pertencendo aos Culicídeos', A Folha Medica, ano 3, no 12, pp. 89-92.

$\mathrm{BC}$

5 originais.

Arquivo Pasta Blepharoceridae. Original (publicado?). Texto em português (sem chave).

Bertha Lutz Em Culicidae, tem outro original datilografados só (da parte concernente aos) simulídeos.

Resumo $\quad$ Review of Applied Entomology, 10:199; 11:19. 
1924 - 'Sur les Rainettes des environs de Rio de Janeiro', Compte Rendus des séances de la Société de Biologie, Paris, 90(3):241.

BAL xerox.

1924 - 'Sur le Dioctophyme renalis', Compte Rendus des séances de la Société de Biologie, Paris, 90(10):696.

BAL

Resumo de xerox. Também em BC. F. W. Bach Centralblatt für die Gesamte Hygiene, 9:363, 1925.

(1924) - 'Sammeln, Präparieren, Untersuchen und Bestimmen der hygienisch wichtigen Insekten'. Em Rudolf Kraus und Paul Uhlenhuth. Handbuch der Mikrobiologischen. Technik. 3:2135-82, il. Berlin und Wien (2a ed., 1929).

BAL

1 exemplar cópia fotostática (sob nํ137). Também em BC.

1924 - 'Estudos sobre a evolução dos Endotrematodes brasileiros. Parte especial. I. Echinostomidae. Untersuchungen ueber die Entwickelungsgeschichte brasilianischer Trematoden. Spezieller Teil. Echinostomidaé, Memórias do Instituto Oswaldo Cruz, t. 17, nำ1, pp. 55-73 (português), 75-93 (alemão), pls. 5-12.

BAL xerox. Também em BMN e BC.

1925 - 'Phyllomedusa appendiculate. Phyllomedusa hahiana borythomantis adspersa', Compte Rendus des séances de la Société de Biologie, Paris, séance du 6 avril 1925, vol. 93, no 20, juin 12, 1925, p. 139; no 22, juin 26, p. 213.

BAL

(?).

1925 - 'Dioctophyme renalis (Eustrongylus gigas)', Compte Rendus des séances de la Société de Biologie, Paris, 93(21):39-40.

BAL xerox. Também em BC.

1925 - 'Batraciens du Brésil. Diagnoses d'espèces nouvelles', Compte Rendus des séances de la Société de Biologie, Paris, 93(22):137-9, 211-4. Publicado também como Espécies novas de Batrachios brasileiros. New species of Brazilian Batrachians. Preliminary note (Translation). Publicação do Instituto Oswaldo Cruz, 16p. Rio de Janeiro.

BAL xerox. Também BC, refs. 597.6 e 11519, ambos de 1926; e BC.

Reimpresso das Memórias do Instituto Oswaldo Cruz, t. XVIII, fas. 1, ano 1925. Rio de Janeiro, Manguinhos (BN - III - 191,2,7, nº 13). 
1928 - Em colaboração com o dr. Gualter A. Lutz: Bilharziazis oder Schistosomum infektionen. Jena, Gustav Fischer und Berlin und Wien, Urban \& Schwarzenberg, 1928, pp. 873-906. Originalmente cap. XXIII de W. Kolle (Frankfurt a. M.), R. Kraus (Wien), P. Uhlenhuth (Freiburg i. Br.), Handbuch der pathogenen Mikroorganismen. Begründet von W. Kolle und A. V. Wassermann. Jena, Gustav Fischer/ Berlim e Viena, Urban \& Schwarzenberg, dritte Auflage (3ํeㄹ.), vol. 6, no (Lfg.) 27, pp. 873-906; 6 figs. no texto e 5 pranchas ( $\mathrm{Nos}^{\mathrm{os}} 1$ a 5 ).

BAL 36 originais da separata. Também em BN, IV - 217,7,36, no 1; BC, ref. 12847.

1929 - 'Dous phyllopodos observados no Rio Grande do Norte'. Supplemento das Memórias do Instituto Oswaldo Cruz, n⿳ 5, jan.-fev. 1929, pp. 3-9; pranchas 1 a 3.

BAL 116 originais da separata. Também em BC.

Centenário consta que há "resumos em francês, inglês e alemão".

1929 - 'Nova contribuição para o conhecimento do cyclo evolutivo das holostomideas ou Strigeidas. Communicação preliminar do dr. Adolpho Lutz. Neuer Beitrag zur Kenntnis des Entwicklungszyclus der Holostomiden oder Strigeiden'. Supplemento das Memórias do Instituto Oswaldo Cruz, no 8, 22.6.1929, pp. 128-30 (português); 1 página não numerada, resumo em alemão.

BAL 96 originais da separata em português e 73 em alemão. Também em BC.

1929 - 'Sammeln, Präparieren, Untersuchen und Bestimmen der hygienisch wichtigen Insekten', cap. XIII de W. Kolle (Frankfurt a. M.), R. Kraus (Wien), P. Uhlenhuth (Freiburg i. Br.), Handbuch derpathogenen Mikroorganismen. Begründet von W. Kolle und A. v. Wassermann. Dritte Auflage (3 ed.). Jena, Gustav Fischer/Berlim e Viena, Urban \& Schwarzenberg, vol. 10, no (Lfg.) 37, pp. 551-90; 25 figs no texto. Segunda publicação.

BAL 23 originais da separata +1 exemplar cópia fotostática (sob no 154).

Arquivo Mais 2 separatas.

Bertha Lutz

1929 - 'Une nouvelle espèce de Hyla'. Extrait des Comptes rendus des séances de la Société de Biologie. Société brésilienne de biologie. Séances des 30 janvier, 27 février et 27 mars 1929, t. 101, no 24 , pp. 943.

BAL 4 originais da separata. Também em BC.

1929 - 'Reminiscências sobre a febre amarella pelo dr. Adolpho Lutz (chefe de serviço do Instituto Oswaldo Cruz)', em 4⿳⺈⿴囗十一 Conferência Sul-Americana de Hygiene, Pathologia e Microbiologia, vol. 1, $2^{\underline{a}}$ parte, pp. 803-18. Rio de Janeiro.

BAL 1 cópia fotostática do Serviço de Documentação, Reitoria da USP, Dep. de Cultura e Ação Social, ref. 553-54.

OBS. Na caixa 6 , pasta $212 \mathrm{C}$, maço 1: originais datilografados emendados à mão pelo próprio Lutz.

1929 - 'Taxonomia e biologia do genero Cyclorbamphus. Taxonomy and biology of the genus Cyclorbamphus. Reimpresso das Memórias do Instituto Oswaldo Cruz, vol. 22, no 1 . Rio de Janeiro, Manguinhos, 6 de maio de 1929, pp. 5-16 (português), 17-25 (inglês), estampas col. e pb. nºs 1 a 5 .

BAL 1 original da separata. Também, BC. 
JAIME L. BENCHIMOL, MAGALI R. SÁ, JOHANN BECKER et alii

1932 - 'Sur la biologie des batraciens du Brésil (Leptodactylus parvulus; Dendrophryniscus brevipollicatus)', Comptes Rendus des séances de la Société de Biologie, Paris, 109(9):755-6.

BAL xerox. Também em BC.

1932 - 'Transmissão e prophilaxia da lepra. Palestra feita pelo prof. dr. Adolpho Lutz na Rádio Sociedade do Rio de Janeiro', Boletim da Sociedade de Assistencia aos Lazaros e Defesa contra a Lepra, vol. 4, nº 3, p. 15. São Paulo.

BAL 1 original do periódico. Textos datilografados, inclusive "originais primeiros". Caixa 20, pasta 252, maço 8.

1933 - 'Considerações sobre o Distomum tetracystis Gastaldi e formas semelhantes, erroneamente chamadas Agamodistomos. Zur Kenntnis des Distomum tetracystis Gastaldi und aehnlicher Formen, die faelschlich als Agomodistomum bezeichnet werden', Memórias do Instituto Oswaldo Cruz, vol. 27, nº 1, pp. 33-49 (português), 50-60 (alemão), estampas I a V.

BAL 19 originais da separata em português e alemão.

1933 - 'A transmissão da lepra pelos mosquitos. Conferência de unificação da Campanha contra a Lepra', Jornal do Brasil, 1.10.1933.

BAL 1 recorte original do Jornal do Brasil e 1 cópia fotostática do Jornal do Commercio do Serviço de Documentação, Reitoria da USP, Dep. de Cultura e Ação Social, ref. 2425. Recorte original do Jornal do Commercio na caixa 22, pasta 256, maço 5. Com tradução para o inglês datilografada e corrigida (provavelmente por Bertha).

1934 - 'Notas sobre Dicranocercarias brazileiras. Beobachtungen über Brasilianische Dicranocercarien', Memórias do Instituto Oswaldo Cruz, vol. 27, nº 4, pp. 349-76 (português), 377-402 (alemão), estampa no 80 .

BAL 78 originais da separata em português e alemão. Também em BC.

1934 - 'Notas sobre espécies brasileiras do genero Bufo. - Zur Kenntniss der Brasilianischen Kroeten', Memórias do Instituto Oswaldo Cruz, vol. 28, no 1, pp. 111-33, 135-59, 15 pls.

BAL xerox. Também em BC.

1934 - 'Transmission du Schistosoma mansoni dans l'état de Minas Geraes (Brésil) par le Planorbis centimetralis'. Extrait des Comptes Rendus des séances de la Société de biologie. Société de biologie de Rio de Janeiro. Séances des 28 mars et 25 avril 1934, t. 116, no 26, p. 1149.

BAL 52 originais da separata. Também em BC.

1934 - 'Coccidioides - Infektion mit Lokalisation in der Mundschleimhaut. Erste in Südamerika beobachtete Fälle. Beitrag zur Geschichte der Hyphoblastomycosis americana', Memórias do Instituto Oswaldo Cruz, vol. 28, no 4, pp. 585-601.

BAL 57 originais da separata. 1 cópia fotostática do Serviço de Documentação, Reitoria da USP, Dep. de Cultura e Ação Social, ref. 121-54 SY 331. Também em BC. 
1936 - Em colaboração com G. M. de Oliveira Castro, 'Considerações sobre a transmissão de doenças por sugadores de sangue'. Reimpresso de A Folha Medica, ano 17, nº 21, 25.7.1936, pp. 320-8. Número especial de doenças tropicaes e infectuosas.

BAL 1 cópia fotostática +2 originais da separata. Também em BC.

Arquivo Mais 1 original da separata. Pasta Entomologia Médica: originais datilografados

Bertha Lutz incompletos.

1936 - 'Entstehung, Ausbreitung und Bekämpfung der Lepra', Annaes da Academia Brasileira de Sciencias, vol. 8, no 2, pp. 87-125.

BAL 7 exemplares +1 cópia fotostática (com resumo em português) (rótulo indicando $\mathrm{n}^{\mathrm{o}}$ 179). Também em BC.

OBS. Anexo ao trabalho encontra-se a seguinte anotação de Bertha Lutz: "Trabalho importante. Concatenação das idéias de Adolpho Lutz sobre a lepra escrito em alemão porque a colaboradora-secretária era alemã." Originais manuscritos e parcialmente datilografados na caixa 20, pasta 252, maço 10. Originais datilografados, 56p., alguns corrigidos à mão, na caixa 19, pasta 74, maço 3.

1936 - 'A transmissão da lepra e suas indicações prophylaticas. - Transmission of leprosy and prophylactic indications', Memórias do Instituto Oswaldo Cruz, vol. 31, nº 2, pp. 373-81 (português), 383-90 (inglês).

BAL 2 exemplares +1 exemplar da separata em português +3 exemplares em inglês.

Centenário O trabalho acima está referido como: 'resumo de Entstehung, Ausbreitung und Bekämpfung der Lepra, publicado em 1936 nos Annaes da Academia Brasileira de Sciencias, vol. 8, nำ 2, pp. 87-125'. Duas cópias datilografadas em inglês, do resumo, na caixa 22, pasta 256, maço 2. Originais datilografados na caixa 20, pasta 252, maço 9 da versão inglês/português.

Reimpresso Boletim da Campanha contra a Lepra, nos 3 e 4, maio-jun. 1936, pp. 11-3, Distrito Federal/São Paulo.

1937 - Em colaboração com G. M. de Oliveira Castro, 'Sobre uma especie nova do gênero Laphriomyia Lutz, e descripção do macho de L. mirabilisLutz. (Diptera: Tabanidae)', Memórias do Instituto Oswaldo Cruz, vol. 32, no 2, maio 1937, pp. 231-3.

BAL 2 exemplares da separata + 1 cópia fotostática (rótulo com no 180). Também em BC.

1937 - Em colaboração com G. M. de Oliveira Castro, 'On Hyla aurantiaca Daudin and Sphoenorbynchus Tschudi and on two allied Hylas from South-Eastern Brazil', Annais da Academia Brasileira Scientífica, vol. 10, no 2, pp. 175-94, 7 figs. Com resumo em português.

BAL xerox.

1937-38 - 'No control of leprosy without anti-mosquito campaign by prof. dr. Adolpho Lutz'. Trabalho enviado ao Cairo, "provavelmente inédito".

BAL Texto datilografado 7p. Na primeira página, anotado à mão 1937-38. Cairo, 21-28.3.1938. A conferência internacional sobre lepra naquela capital foi agendada por decreto do governo do Egito, em 1936 (Correio da Manhã, 16.11.1937). Pasta 254, maço 5. 
1943 - 'Contribuição à história da medicina no Brasil segundo os relatórios do dr. Adolpho Lutz como diretor do Instituto Bacteriológico de S. Paulo (1893-1908). Apresentação de Henrique Aragão, diretor interino do IOC e Introdução de Bertha e Gualter A. Lutz. Cólera Asiático em São Paulo - Disenteria', Memórias do Instituto Oswaldo Cruz, vol. 39, nº 2, pp. 177-241. Rio de Janeiro, Imprensa Nacional.

BAL 2 exemplares da separata.

OBS. Na caixa 27, pasta 8, maço 2 encontram-se as notas utilizadas por Gualter e Bertha para preparar o relato sobre a disenteria. Resumos e transcrições manuscritos e datilografados de autores que trataram de disenteria. Listagem de bibliografia que pode ter sido manuscrita por Amy Lutz, aparentemente exaustiva para o período ca. 1887-1904 (inclui um trabalho de Francisco Fajardo publicado na Alemanha em 1896). Um documento intitulado 'Summary' traz sumários em inglês das partes dos relatórios de Lutz concernentes às enterites e hepatites. Textos datilografados na caixa 27, pasta 8 , maço 4 e pasta 25 , maços 1 e 2 .

1943 - 'Contribution to the history of medicine in Brazil. The early work and reports of dr. Adolpho Lutz, director of the Bacteriological Institute of the State of São Paulo from 1893 to 1908. Foreword - Cholera - Disentery'. Reprint from Memórias do Instituto Oswaldo Cruz, vol. 39, n⿳⺈ 2, pp. 191-252. Rio de Janeiro, Imprensa Nacional.

BAL 2 exemplares da separata. Texto datilografado sobre disenteria na caixa 27 , pasta 8 , maço 3 .

1945 - 'Uma micose pseudococcídica localizada na boca e observada no Brasil. Contribuição ao conhecimento das hifoblastomicoses americanas', Anais Brasileiros de Dermatologia e Sifilografia, vol. 20, nº 2, pp. 131-53. Publicação trimestral sob os auspícios da Sociedade Brasileira de Dermatologia e Sifilografia. Com sumário em inglês.

BAL 2 exemplares da separata.

OBS. Excetuando-se o parágrafo de introdução, acrescentado, e dois parágrafos do texto original de 1908, suprimidos, é idêntico a 'Coccidioides - Infektion mit Lokalisation in der Mundschleimhaut. Erste in Südamerika beobachtete Fälle. Beitrag zur Geschichte der Hyphoblastomycosis americana', Memórias do Instituto Oswaldo Cruz, vol. 28, no 4, 1934, pp. 585-601. Ver também original em 1908.

1946 - 'Contributions to the history of medicine in Brazil. Dermatological reminiscences', Reimpresso das Memórias do Instituto Oswaldo Cruz, t. 44, no 1. Rio de Janeiro, Imprensa Nacional, 1946, pp. 1-12.

BAL 5 originais da separata. Caixa 20: originais datilografados.

1946 - 'Contribuição à história da medicina no Brasil. Reminiscências dermatológicas', Memórias do Instituto Oswaldo Cruz, vol. 44, nำ 1-6.

BAL 1 exemplar. Caixa 20, pasta 252, maço 13: originais datilografados. Também em BC.

Editorial J. Rodrigues Coura, 'Adolpho Lutz - Autor e pioneiro do método de sedimentação para o diagnóstico de ovos do S. Mansoni nas fezes. Falecido em 6.10.1940', Rev. Soc. Bras. Med. Trop., vol. 7, no 6, 1973, p. 333. 